\title{
Toxicity and Antifeedant Activity of Calotropis gigantea L. Leaf Extract Against Plutella xylostella L. (Lepidoptera: Plutellidae)
}

\author{
Nur Khasanah $^{1 *}$, Edhi Martono ${ }^{2}$, Y Andi Trisyono ${ }^{2}$, Arman Wijonarko $^{2}$ \\ ${ }^{1}$ Faculty of Agriculture, Tadulako University, Palu, Central Sulawesi 94118, Indonesia \\ ${ }^{2}$ Faculty of Agriculture, Gadjah Mada University, Yogyakarta 55281, Indonesia
}

Corresponding Author Email: khasanah@untad.ac.id

https://doi.org/10.18280/ijdne.160609

Received: 7 November 2021

Accepted: 8 December 2021

\section{Keywords:}

antifeedant, compound composition, leaf dipping, spraying

\begin{abstract}
Many parts of the Calotropis gigantea plant are known to contain bioactive compounds, but leaves contain the most. This study aimed to determine the toxicity and antifeedant activity of $C$. gigantea leaves against Plutella xylostella. The study was carried out from November 2019 to July 2020. Toxicity was tested using the leaf dipping and spraying methods. Antifeedant activity was tested using a no-choice test and a choice test. Identification of the compound composition of the leaf extract of $C$. gigantea was carried out at the Integrated Research and Testing Laboratory, Gadjah Mada University. Extract toxicity data obtained were analyzed by Probit analysis. The results showed that the antifeedant activity of $C$. gigantea leaf extract a no-choice and with choice at each concentration had a significant effect on the consumption of $P$. xylostella larvae rations. The toxicity $\left(\mathrm{LC}_{50}\right)$ of the leaf extract of $C$. gigantea to $P$. xylostella by the dipping method was $2,958 \mu \mathrm{gl}^{-1}$ while the spraying application was $3.944 \mu \mathrm{gl}^{-1}$. The composition of chemical compounds contained in the leaf extract of $C$. gigantea is saponins, alkaloids, flavonoids, tannins, phenols, terpenoids. With the composition of these chemical compounds, the leaf extract of $C$. gigantea has the potential as a source of vegetable insecticide compounds against $P$. xylostella.
\end{abstract}

\section{INTRODUCTION}

Plants and insects have a long history of interacting with each other, especially phytophagous insects that consume plant tissues. Plants, when interacting with herbivores, produce secondary metabolites to protect themselves from herbivores or pathogens [1]. Plants are sources of various chemical compounds with rich bioactivities [2]. Plant-based chemical compounds are produced by above and belowground plant tissues, while both support the defenses mechanism of plants against insects [3]. Chemical compounds related to plant defense (secondary metabolites) include alkaloid, saponin, tannin, phenol and terpenoids. Secondary metabolites act as toxics, repellence, or anti-nutritious against herbivores and are a source of promising biopesticides for pest management [1].

The use of secondary metabolites for pest management is an effective alternative solution. According to Campos et al. [4], secondary metabolite compounds have several mechanisms of action against targeted insects and have low toxicity on nontarget organisms. Secondary metabolites act as toxics, deterrents, repellents and reduce nutritional content [5]. Toxic compounds from plant secondary metabolites can be used as botanical insecticides [1]. Many research has shown plant extracts as potential bio-insecticides. Several plant families that have been recognized and formulated into commercial botanical insecticides, include Amaranthaceae, Asteraceae, Fabaceae, Meliaceae, Piperaceae, Salicaceae, Solanaceae [6].

Calotropis gigantea belongs to Asclepiadaceae. C. gigantea grows across Southeast Asia, Pacific Island, Australia, South
America and Africa [7]. C. gigantea is known as a weed that produces white sap from its whole structure and has potential as a medicinal plant and its activity as insecticide. $C$. gigantea belongs to Asclepiadaceae that includes 280 genera and approximately 2,000 species. Calotropis gigantea (Linn) $R$. Br. and $C$. procera (Ait) R.Br. are two interrelated species. Both have similar botanical appearances and pharmacological effects [8]. Plant parts of $C$. procera and $C$. gigantea are toxic [9]. Compounds contained in $C$. gigantea leaf extract consist of alkaloids, steroids, terpenoid, flavonoid, tannin, and phenol $[7,8]$.

C. gigantea leaves are parts that contain the most phytochemicals compared to other plant parts. Saps contain secondary metabolites that are used for defenses against herbivores and pathogens [10]. Bioactive compounds within $C$. gigantea cause it to resistant against insect and phytopathogen [11]. Toxicity test $C$. gigantea leaf against Helicoperva armigera showed that leaves had highest larvicidal activity compared to other plant parts and had antifeedant activity against $H$. armigera [12]. Based on these activities, $C$. gigantea leaf extracts have potential as a source of bioactive compounds with insecticidal properties against Plutella xylostella. This research aims to determine toxicity and antifeedant activity of $C$. gigantea leaf extract against $P$. xylostella. Considering the importance of food safety for consumers and the environment, finding sources of bioinsecticide is very important. This research hopes to provide information for the use of potential of active ingredients in C. gigantea as a bioinsecticide, especially as a toxin and antifeedant against $P$. xylostella. 


\section{MATERIALS AND METHODS}

\subsection{Insect collection and rearing}

P. xylostella was collected from Cangkringan Village, Yogyakarta Province and kept in a greenhouse. Maintenance includes planting seeds of bok choy (Brassica rapa var. chinensis) as food and as a place to lay $P$. xylostella eggs. Maintenance of bak choy plants by giving organic fertilizer which aims to obtain good plant growth [13].

Four plants were placed in four rearing boxes measuring 25 x $40 \mathrm{~cm}$ along with twelve pairs of $P$. xylostella imago which were fed $10 \%$ honey solution. the. Every three days, the plants were placed in an oviposition box measuring $40 \times 60 \mathrm{~cm}$. Plants are replaced until the imago dies. Thus, it was obtained that the larval needs of 4,400 individuals would be met through the insect collection and rearing.

\subsection{Calotropis gigantea leaf extract}

Extraction was done using a maceration method [14]. As much as $350 \mathrm{~g}$ of macerated $C$. gigantea leaf was added into a container, $1.4 \mathrm{~L}$ of ethanol was added and stirred to prevent sedimentation. The product was then sealed and stored in room temperature and reduced exposure to direct sunlight. Immersion was done for 48 hours, filtered using filter paper and Buchner funnel. Solution and solvent were separated using a Vacum Rotary evaporator (Heidolph; Weirtheim and Waterbath Cole-Parmer type 7049-05) at temperatures 40 $180^{\circ} \mathrm{C}$ and $160-280 \mathrm{rpm}$ for 3 hours.

\subsection{Toxicity test}

$P$. xylostella larvae were tested using a feeding assay. The bok choy leaves were washed and made into circular leaf discs with a diameter of $2.5 \mathrm{~cm}$. Petri dishes (diameter $9 \mathrm{~cm}$ height $2 \mathrm{~cm}$ ) were used as bioassay arena. Concentration used were $15,7.5,3.75,1.875,0.937 \mu \mathrm{gl}^{-1}$ and control. Five bok choy leaf disc was immersed into solutions for 1 minute and air dried on a petri dish. Twenty larvae were placed on to the petri dish according to designated treatment. Mortality percentage was observed every 24, 48, and 72 hours. Contact assay was done using a spraying assay. Concentration used were 20, 10, 5, 2.5, $1.250 \mu \mathrm{gl}^{-1}$. Twenty larvae were placed on a petri dish and each concentration was replicated 10 times. As much as $2 \mathrm{ml}$ of $C$. gigantea leaf extract were sprayed using Potter Precision Laboratory Spray Tower (Burkard Manufacturing Co. Ltd. Rickmansworth Herts. UK) with aperture nozzle of 0.6985 m, pressure at $1.12 \mathrm{~kg} \mathrm{~cm}^{2}$. Percentage of mortality was observed every 24,48 , and 72 hours.

\subsection{Antifeedant test}

Antifeedant bioassay was done using a no-choice antifeedant test and choice test [15]. Bok choy leaves were washed and made into $2.5 \mathrm{~cm}$ disc using a cork borer and placed on a petri dish. Concentration used were 15, 7.5, 3.75, $1.875,0.937 \mu \mathrm{g} \mathrm{l}^{-1}$ and control. In the no-choice test, six-leaf discs were immersed in $C$. gigantea leaf extract for 1 minute according to designated concentration and air-dried. Twenty larvae were placed into petri dishes according to designated treatments. Choice test was done using 3 bok choy leaf that were immersed in $C$. gigantea according to designated concentration and 3 leaf discs immersed in distilled water for 1 minute. Treated and untreated leaves were place alternated within the petri dish in a circular pattern with the middle part empty for placing larvae. Twenty larvae were placed in the space and allowed to choose leaf disc. Each treatment was replicated 10 times. Area of consumed leaves were calculated using previous stated method. Observations were done every 3,6 and 9 hours after treatment.

\subsection{Identification of chemical compounds within $C$. gigantea leaves}

Two grams of $C$. gigantea were extracted and then tested to determine the class of compounds which included total alkaloids, tannins, phenols, flavonoids, saponins and quantitative tests of terpenoids. The total alkaloids, tannins, phenols, flavonoids, and saponins were performed using spectrophotometry, while terpenoids were performed using thin layer chromatography [16].

\subsection{Data analysis}

Probit analysis [17] was done using SAS JMP Pro.v13.2.1 to obtain $\mathrm{LC}_{50}$ and $\mathrm{LC}_{95}$ on test insects. Antifeedant was calculated using formula [16]: antifeedant no choice test $=(\mathrm{C}$ $\mathrm{T}) / \mathrm{C} \times 100 \%$, antifeedant choice test $=(\mathrm{C}-\mathrm{T}) /(\mathrm{C}+\mathrm{T}) \times 100$. $\mathrm{C}=$ leaf area consumed leaf in control, $\mathrm{T}=$ leaf area consumed from treatment. ANOVA was done using SPSS 16.0 at $\alpha=5 \%$ and if significantly different, a post-hoc test using DMRT was done.

\section{RESULT AND DISCUSSION}

\subsection{Toxicity test}

Toxicity against $P$. xylostella from the leaf dipping bioassay (Table 1) demonstrated probit analysis with $\mathrm{LC}_{50}$ estimation of $2.958 \mu \mathrm{gl}^{-1}$ with $95 \% \mathrm{CI}$ between $2.415 \mu \mathrm{gl}^{-1}$ to $3.565 \mu \mathrm{gl}^{-1}$. Toxicity of $C$. gigantea extract showed $P$. xylostella larvae was higher as concentration increased even though the less leaf consumed. Research [18] showed high concentration of Argemone ochroleuca extract resulted in high mortality of Spodoptera frugiperda larvae even though only a small portion of leaves are consumed. A decrease in feeding rates is a result of feeding deterrent or sublethal toxicity [19]. This implies that insect death is a cause of a combination between starvation and compounds contained in $C$. gigantea extract. According to the study [20], all parts of the $C$. gigantea plant contain toxins in the leaves, flowers, sap, stems and roots. Bioactive compounds cause poisoning, knockdown, locomotive instability, paralysis and slow death, and inhibition of eating behavior [21]. Symptoms of $P$. xylostella larvae after consuming diets were slower to no movement of larvae from diets and larvae color turn pale green to light brown to blackish brown and finally die. Toxicity of $P$. xylostella larvae using spraying application (Table 1 ) had a lethal concentration $\left(\mathrm{LC}_{50}\right)$ estimation of $3.944 \mu \mathrm{gl}^{-1}$ with $95 \%$ CI between $3.219 \mu \mathrm{gl}^{-1}$ to $4.794 \mathrm{\mu gl}^{-1}$. After application, larvae moved in a random direction but became calmer when moved to untreated diets. However, after 24 hours, several larvae died and mortality increased until 48 hours with symptoms of exposed insects to experience corrosion, browning, and died. 
Table 1. Toxicity of Calotropis gigantea leaf extract using dipping and spraying method on $3^{\text {rd }}$ instar Plutella xylostella

\begin{tabular}{cccccc}
\hline Method & Volume & n & Slope $( \pm$ SE) & LC $_{\mathbf{5 0}}$ & df \\
\hline Dip & 40 & 1200 & $0.480( \pm 0.058)$ & $2.958(2.4146-3.565)$ & 3 \\
Spray & 40 & 1200 & $0.430( \pm 0.042)$ & $3.944(3.2198-4.7947)$ & 3 \\
\hline
\end{tabular}

Dip: Bok choy leaf discs were dipped into Calotropis gigantea leaf extract, larvae were placed into containers with diets and observed 72 hours before mortality count. Spraying: Larvae were placed into a petri dish and sprayed with Calotropis gigantea leaf extract

Table 2. The antifeedant activity of Calotropis gigantea leaf extract using choice and no-choice test of third instar Plutella xylostella larvae $(\mathrm{n}=1000)$ at 3,6 and 9 hours

\begin{tabular}{|c|c|c|c|c|c|c|}
\hline \multirow{3}{*}{ Concentration $\left(\mu \mathrm{gl}^{-1}\right)$} & \multicolumn{6}{|c|}{ Antifeedant index + SE } \\
\hline & \multicolumn{3}{|c|}{ No-Choice test } & \multicolumn{3}{|c|}{ Choice test } \\
\hline & 3 hours & 6 hours & 9 hours & 3 hours & 6 hours & 9 hours \\
\hline 15 & $83.30 \pm 5.43^{\mathrm{b}}$ & $87.72 \pm 2.97^{\mathrm{d}}$ & $89.83 \pm 1.63^{\mathrm{d}}$ & $91.79 \pm 5.43^{\mathrm{a}}$ & $87.95 \pm 4.85^{\mathrm{a}}$ & $80.32 \pm 6.27^{a}$ \\
\hline 7.5 & $79.19 \pm 3.93^{\mathrm{b}}$ & $73.47 \pm 7.01^{\mathrm{cd}}$ & $81.61 \pm 4.33^{\mathrm{d}}$ & $72.46 \pm 7.01^{\mathrm{ab}}$ & $64.84 \pm 6.96^{\mathrm{a}}$ & $66.74 \pm 5.53^{a}$ \\
\hline 3.75 & $74.83 \pm 4.55^{\mathrm{b}}$ & $48.98 \pm 9.24^{\mathrm{bc}}$ & $63.15 \pm 7.41^{\mathrm{c}}$ & $63.63 \pm 7.58^{\mathrm{ab}}$ & $61.98 \pm 6.72^{\mathrm{ab}}$ & $58.20 \pm 5.49^{\mathrm{ab}}$ \\
\hline 1.875 & $49.05 \pm 7.26^{\mathrm{a}}$ & $34.05 \pm 9.27^{\mathrm{ab}}$ & $29.21 \pm 9.71^{\mathrm{b}}$ & $63.62 \pm 7.90^{\mathrm{bc}}$ & $57.68 \pm 6.72^{\mathrm{b}}$ & $48.21 \pm 5.56^{\mathrm{b}}$ \\
\hline 0.937 & $38.23 \pm 6.41^{\mathrm{a}}$ & $11.24 \pm 13.90^{\mathrm{a}}$ & $3.82 \pm 3.39^{\mathrm{a}}$ & $48.82 \pm 8.10^{c}$ & $46.08 \pm 5.81^{\mathrm{c}}$ & $48.09 \pm 5.26^{\mathrm{c}}$ \\
\hline
\end{tabular}

Note: SE (Standard error). Mean antifeedant index \pm SE followed by di same letter in the same column at each observation time were not significantly different based on Duncan $(\mathrm{P}<0.05)$

Toxicity of $C$. gigantea leaf extract when applied using spraying method caused higher mortality as concentration increased. Mortality level is affected by concentration, the content of bioactive compounds and physiological characteristics of $P$. xylostela. In general, toxicity is affected by dosage, application time, and individual characteristics, such as the sensitivity of action cites, and development stage [22]. P. xylostella larvae have soft and fatty cuticles causing compounds in the extract can easily penetrate the cuticle. Cuticles have physical characteristics consisting of chitin, protein, water, mineral, and tanner substance and relevance that affect the mechanical or elasticity aspect of the cuticle [23]. The structure and thickness of the cuticle affect insecticide penetration levels [24].

\subsection{Antifeedant activity}

The antifeedant activity of the non-choice test (Table 2) at 3 hours after application of $C$. gigantea extract at each concentration showed a different index of antifeedant. Concentration 15 to $0.937 \mu \mathrm{gl}^{-1}$ significantly $(\mathrm{p}<0.05$ ) reduce leaf consumption of $P$. xylostella. Therefore, $15,7.5,3.750 \mu \mathrm{g}$ $1^{-1}, C$. gigantea leaf extract decreased leaf consumption of $P$. xylostella by $83.30 \%, 79.19 \%$ and $74.83 \%$ compared to concentration of 1.875 and $0.937 \mu^{-1}$ decreased consumption of 49.05 and $38.23 \%$. Antifeedant activity at 6 hours, $C$. gigantea leaf extract significantly decrease leaf consumption of $P$. xylostella by $87.72 ; 73.47 ; 48.98 ; 34.05$ and $11.24 \%$. The concentration of 15 and $7.5 \mu^{-1}$ demonstrated the highest antifeedant activity compared to other concentrations. Antifeedant active at 9 hours, each concentration of $C$. gigantea leaf extract decreased leaf consumption of $P$. xylostella by $89.83 ; 81.61 ; 63.15 ; 29.21$ and $38.23 \%$. At all observation times ( 3.6 and 9 hours) the antifeedant activity showed a concentration of $15{\mu g^{-1}}^{-1}$ giving the highest antifeedant activity and significantly different with 1.87 and 0.937 at 3 hours and $3.75,1.875$ and $0.937 \mu \mathrm{gl}^{-1}$ at 6 and 9 hours but not significantly different from the others. The concentration of 15 and $7.5 \mu \mathrm{gl}^{-1}$ at 9 hours of $C$. gigantea leaf extract had higher inhibition compared to 3 and 6 hours.

Choice antifeedant activity (Table 2 ) at 3 hours showed that leaf consumption was significantly affected by $C$. gigantea leaf extract by $91.79 ; 72.46 ; 63.6 ; 63.62$ and $48.82 \%$. Choice test at 6 hours demonstrated antifeedant activity by 87.95 ; $64.84 ; 61.98 ; 46.08$ and $45.85 \%$. At 9 hours, antifeedant activity significantly decreases leaf consumption of $P$. xylostella larvae by $80.32 ; 65.20 ; 58.20 ; 48,12$ and $48.09 \%$. At

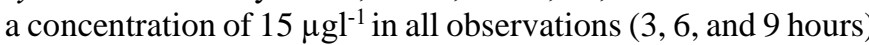
showed the highest antifeedant activity but not significantly

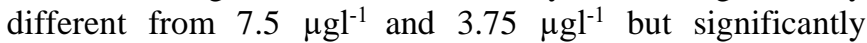
different from the others. The antifeedant activity of $C$. gigantea leaf extract at 6 and 9 hours showed a decrease of inhibition at untreated control. At the beginning, all larvae moved to diets. However, after 2-3 hours, larvae started to consume leaf disc, except for concentration at $15 \mu \mathrm{gl}^{-1}$.

Antifeedant activity from the no-choice test with $C$. gigantea leaf extract caused leaf consumption of $P$. xylostella to decrease based on leaf extract concentrations. Feeding levels decrease respectively to leaf extract concentrations and are consistent with similar research on $H$. armigera [12]. A higher antifeedant index shows a decrease in feeding [25]. At the beginning of this bioassay, larvae moved randomly and did not directly consume disc leaves. Larvae would lightly consume leaves and continue to move again. Results from other research showed that azadirachtin affected $S$. litura selectivity of azadirachtin odor over time [26]. According to [1] chemical compounds in plants have to potency to affect insect behavior by deterrence and repellency.

Antifeedant activity on $P$. xylostella larvae at concentrations of 15 and $7.5 \mu \mathrm{gl}^{-1}$ at 3, 6 and 9 hours showed an increase of inhibition compared to other concentrations. An increase of antifeedant activity at that concentration demonstrated that leaf extract still possessed antifeedant activity against $P$. xylostella. Antifeedant activities at 3,6 and 9 hours showed high antifeedant activity. At concentrations of $15 \mu \mathrm{gl}^{-1}$ at 3 hours showed feeding inhibition by $91.79 \%$; however, at 6 and 9 hours, inhibition decrease to 87.95 and $80.32 \%$.

The antifeedant test was carried out with different methods, namely choice and no-choice. In the no-choice antifeedant test, feed at each concentration was placed in one petri dish and untreated feed was put in another petri dish, then twenty larvae were added in each treatment given the opportunity to consume the provided feed. The untreated feed was intended as a control to be used as a comparison in determining antifeedant activity. While the choice of antifeedant feed was given to each treatment and without treatment was placed in 
the same petri then 20 larvae were added to choose the feed and then the antifeedant activity was measured. Research of [27] showed that essential oil of clove leaves inhibited the feeding of $S$. litura. According to previous researches, secondary metabolites modulate insect behavior [28, 29]. Antifeedant activity stimulates specific feeding resistant nerves chemoreceptors on insect mouth parts that work synergistically with other receptors [25].

According to [30], the appearance, taste and odor of the extract can change the behavior of insects. Biting speed is considered to be more effective as an antifeedant than a repellent Apart from odor, the behavior of $P$. xylostella larvae was also greatly influenced by the concentration and chemical compounds found in the extract. The chemical stimulants that act on certain concentrations against insect receptors might affect host acceptance [31]. The behavior of $P$. xylostella larvae towards the chosen feeds indicated that $C$. gigantea leaf extract is considered a deterrent. Repellent and deterrent compounds in the feeds cause insects to stop feeding [32].

\subsection{Compound group identification in $C$. gigantea leaf extract}

The compound content of $C$. gigantea leaf extract consisted of alkaloids $(0.90 \%)$, tannin $(5.94 \%)$, phenol $(9.88 \%)$, flavonoids $(2.20 \%)$, saponin $(4.95 \%)$, and terpenoid (positive) (Table 3). These results showed that the phytochemicals contained in $C$. gigantea leaves were the secondary metabolites. Research [11], the composition of compounds in $C$. gigantea leaf extracts were alkaloid, carbohydrates, glycoside, phenolic/tannin, protein or amino acid, flavonoid, saponin, sterol, and resin. Alkaloid, saponin, glycoside, tannin, flavonoid, terpenoid are used for plant defense against herbivores and have been reported to possess insecticidal properties [33].

The compounds considered as toxic against $P$. xylostella were saponins, alkaloids, tannins, and terpenoids. Saponins are toxic and important for plant defense [34]. Saponins are toxic and antifeedant [35]. Some saponins form complexes with proteins [36] that inhibit proteinase and affect insect digestion [27]. Saponins indirectly affect the insect gut microbiome, several digesting enzymes, and mucous membranes. Saponins strongly affected lepidoptera cells, especially midgut primer cells [37]. Alkaloids act to defend plants from herbivores [27], is toxic [38], inhibit amylase activity, breaks plasm membranes and causes death [39]. Tannins are also toxic against several insects by affecting the growth and development of insect by binding with protein, decreasing nutrition absorption, and causing lysis in the midgut [40].

The compound composition of $C$. gigantea leaf extract that act as antifeedant is terpenoid, alkaloid, saponins, tannin, phenol and flavonoid.

Table 3. Chemical composition of Calotropis gigantea leaf extract

\begin{tabular}{cc}
\hline $\begin{array}{c}\text { Group of } \\
\text { compounds }\end{array}$ & $\begin{array}{c}\text { A total compound in material }(\% \\
\text { w/w) }\end{array}$ \\
\hline Alkaloid & 0.90 \\
Tannin & 5.94 \\
Phenol & 9.88 \\
Flavonoid & 2.20 \\
Saponin & 4.95 \\
Terpenoid & Positive \\
\hline Note: positive (extract contains Terpenoids)
\end{tabular}

In general, alkaloid is a feeding deterrent for insects [29] [26]. Saponins act as antifeedant [35]. Tannins act as feeding deterrents [40]. Phenol acts as defend compounds against herbivores [41] and can be a potential compound for insect management [38].

\section{CONCLUSION}

C. gigantea leaf extract had contact toxicity and antifeedant activity against $P$. xylostella larvae. Mortality and antifeedant increase as the concentration of $C$. gigantea increased on the no-choice test and choice test. The compound composition of saponin, alkaloid, flavonoid, tannin, phenol, terpenoid within C. gigantea leaf extract determined toxicity and antifeedant activity.

\section{ACKNOWLEDGEMENT}

The author would like to thank the Directorate General of Education and Culture of the Republic of Indonesia for funding the first author doctoral degree through the Beasiswa Unggulan (BUDI-DN). The author would also like to thank Sriyanto Harjanto for assisting throughout the research.

\section{REFERENCES}

[1] Miresmailli, S., Isman, M.B. (2014). Botanical insecticides inspired by plant-herbivore chemical interactions. Trends in Plant Science, 19(1): 29-35. https://doi.org/10.1016/j.tplants.2013.10.002

[2] Altaf, M.M., Ahmad Khan, M.S., Ahmad, I. (2019). Diversity of bioactive compounds and their therapeutic potential. New Look to Phytomedicine, Elsevier, 15-34. https://doi.org/10.1016/B978-0-12-814619-4.00002-1

[3] Mundim, F.M., Alborn, H.T., Vieira-Neto, E.H.M., Bruna, E.M. (2017). A whole-plant perspective reveals unexpected impacts of above- and belowground herbivores on plant growth and defense. Ecology, 98(1): 70-78. https://doi.org/10.1002/ecy.1619

[4] Campos, E.V.R., Proença, P.L.F., Oliveira, J.L., Bakshi, M., Abhilash, P.C., Fraceto, L.F. (2019). Use of botanical insecticides for sustainable agriculture: Future perspectives. Ecological Indicators, 105: 483-95. https://doi.org/10.1016/j.ecolind.2018.04.038

[5] Belete, T. (2018). Defense mechanisms of plants to insect pests: From morphological to biochemical approach. Trends in Technical \& Scientific Research, 2(2): https://doi.org/10.19080/TTSR.2018.02.555584

[6] Velasques, J., Cardoso, M.H., Abrantes, G., Frihling, B.E., Franco, O.L. Migliolo, L. (2017). The rescue of botanical insecticides: A bioinspiration for new niches and needs. Pesticide Biochemistry and Physiology, 143: 14-25. https://doi.org/10.1016/j.pestbp.2017.10.003

[7] Joseph, B., George, J., Jeevitha, M.V., Charles, S. (2013). Pharmacological and biological overview on Calotropis gigantean: A comprehensive review. International Research Journal of Pharmaceutical and Applied Sciences, 3: 219-223.

[8] Jahan, N., Mushir, A., Ahmed, A. (2016). A review on Phytochemical and biological properties of Calotropis 
gigantea (Linn) R.Br. Discovery Phytomedicine, 3(2): 15-21. https://doi.org/10.15562/phytomedicine.2016.32

[9] Al Sulaibi, M.A.M., Thiemann, C., Thiemann, T. (2020). Chemical constituents and uses of Calotropis procera and Calotropis gigantea - A review (Part I - the plants as material and energy resources). Open Chemistry Journal, 7:

$1-15$. https://doi.org/10.2174/1874842202007010001

[10] Ramos, M.V., Demarco, D., da Costa Souza, I.C., de Freitas, C.D.T. (2019). Laticifers, latex, and their role in plant defense. Trends in Plant Science, 24(6): 553-67. https://doi.org/10.1016/j.tplants.2019.03.006

[11] Kumar, P.S., Suresh., E., Kalavath, S. (2013). Review on a potential herb Calotropis gigantea (L.) R. Br. Scholars Academic Journal of Pharmacy, 2(2): 135-43.

[12] Prabhu, S., Priyadharshini, P., Thangamalar, A. (2017). Study on larvicidal effect of different plant parts of milk weed plant (Calotropis gigantea $\mathrm{R}$. Br.) against Helicoverpa armigera. International Journal of Current Microbiology and Applied Sciences, 6(10): 655-60. https://doi.org/10.20546/ijcmas.2017.610.080

[13] Lasmini, S.A., Rosmini, R., Lakani, I., Hayati, N., Nasir, B.H. (2021). Increasing shallot production in marginal land using mulches and coconut Husk Fertilizer. International Journal of Design \& Nature and Ecodynamics, 16(1): 105-10. https://doi.org/10.18280/ijdne.160114

[14] Richardson, P.M., Harborne, J.B. (1985). Phytochemical methods. $\quad$ Brittonia, 37: 309. https://doi.org/10.2307/2806080

[15] Yang, H., Piao, X., Zhang, L., Song, S., Xu, Y. (2018). Ginsenosides from the stems and leaves of Panax ginseng show antifeedant activity against Plutella xylostella (Linnaeus). Industrial Crops and Products, 124: 412-7. https://doi.org/10.1016/j.indcrop.2018.07.054

[16] Chanwitheesuk, A., Teerawutgulrag, A., Rakariyatham, N. (2005). Screening of antioxidant activity and antioxidant compounds of some edible plants of Thailand. Food Chemistry, 92(3): 491-7. https://doi.org/10.1016/j.foodchem.2004.07.035

[17] Finney, D.J. (1971). Probit analysis. Journal of the American Pharmaceutical Association (Scientific Ed), 41(11): 318. https://doi.org/10.1002/jps.3030411125

[18] Martínez, A.M., Aguado-Pedraza, A.J., Viñuela, E., Rodríguez-Enríquez, C.L., Lobit, P., Gómez, B. (2017). Effects of ethanolic extracts of Argemone ochroleuca (Papaveraceae) on the food consumption and Development of Spodoptera frugiperda (Lepidoptera: Noctuidae). Florida Entomologist, 100(2): 339-345. https://doi.org/10.1653/024.100.0232

[19] Cerda, H., Carpio, C., Ledezma-Carrizalez, A.C. Sánchez, J., Ramos, L., Muñoz-Shugulí, C., Andino, M., Chiurato, M. (2019). Effects of aqueous extracts from amazon plants on Plutella xylostella (Lepidoptera: Plutellidae) and Brevicoryne brassicae (Homoptera: Aphididae) in Laboratory, Semifield, and field trials. Journal of Insect Science, 19(5): 8 https://doi.org/10.1093/jisesa/iez068

[20] Sharma, S., Kumari, A., Sharma, M. (2016). Comparative GC-MS analysis of bioactive compounds in methanolic extract of Calotropis gigantea (L) W.T. Aiton Leaf and Latex. International Journal of Pharmacognosy and Phytochemical Research, 8(11): $1823-1827$.
[21] Rattan, R.S. (2010). Mechanism of action of insecticidal secondary metabolites of plant origin. Crop Protection, 29(9): https://doi.org/10.1016/j.cropro.2010.05.008

[22] Matsuura, H.N., Fett-Neto, A.G. (2015). Plant Alkaloids: Main features, toxicity., mechanisms of action. In: Gopalakrishnakone, P., Carlini, C.R., Ligabue-Braun, R., editors. Plant Toxins, Springer Netherlands, Dordrecht. 1-15. https://doi.org/10.1007/978-94-007-6728-7_2-1

[23] Politi, Y., Bar-On, B., Fabritius, H.O. (2019). Mechanics of arthropod cuticle-versatility by Structural and compositional variation. In: Estrin, Y., Bréchet, Y., Dunlop, J., and Fratzl, P., editors. Architectured Materials in Nature and Engineering, Springer International Publishing, Cham, 287-327. https://doi.org/10.1007/978-3-030-11942-3_10

[24] Yahouédo, G.A., Chandre, F., Rossignol, M., Ginibre, C. Balabanidou, V., Mendez, N.G.A. (2017). Contributions of cuticle permeability and enzyme detoxification to pyrethroid resistance in the major malaria vector Anopheles gambiae. Scientific Reports, 7: 11091. https://doi.org/10.1038/s41598-017-11357-z

[25] Subramanian, A., Tennyson, S. (2013). Antifeedant activity, developmental indices and morphogenetic variations of plant extracts against Spodoptera litura (Fab) (Lepidoptera: Noctuidae). Journal of Entomology and Zoology Studies, 1(4): 87-96.

[26] Qin, D., Zhang, P., Zhou, Y., Liu, B., Xiao, C., Chen, W. (2020). Antifeeding effects of azadirachtin on the fifth instar Spodoptera litura larvae and the analysis of azadirachtin on target sensilla around mouthparts. Archives of Insect Biochemistry and Physiology, 103(4): 1-12. https://doi.org/10.1002/arch.21646

[27] Fateha, R.N., Grasela, M., Ichwan, M.N., Purwanti, E.W., Kurniasari, I. (2020). Larvicidal and antifeedant activities of clove leaf oil against Spodoptera litura (f.) on soybean. Jurnal Hama dan Penyakit Tumbuhan Tropika, 21(1): 20-25. https://doi.org/10.23960/j.hptt.12120-25

[28] Ajayi, O.E., Balusu, R., Morawo, T.O., Zebelo, S., Fadamiro, H. (2015). Semiochemical modulation of host preference of Callosobruchus maculatus on legume seeds. Journal of Stored Products Research, 63: 31-37. https://doi.org/10.1016/j.jspr.2015.05.003

[29] Wink, M. (2018). Plant secondary metabolites modulate insect behavior-steps toward addiction? Frontiers in Physiology, 9 :

364. https://doi.org/10.3389/fphys.2018.00364

[30] Gharsan, F.N. (2019). A Review of the bioactivity of plant products against Aedes aegypti (Diptera: Culicidae). Journal of Entomological Science, 54(3): 256. https://doi.org/10.18474/JES18-82

[31] Neog, K., Unni, B., Ahmed, G. (2011). Studies on the influence of host plants and effect of chemical stimulants on the feeding behavior in the Muga Silkworm, Antheraea assamensis. Journal of Insect Science, 11(1): 1-16. https://doi.org/10.1673/031.011.13301

[32] Shivkumara, K.T., Roy, S., Manipel, P., Manjes, G.N. (2019). Botanical insecticides; prospects and way forward in India: A review. Journal of Entomology and Zoology Studies, 7(3): 206-211.

[33] Hikal, W.M., Baeshen, R.S., Said-Al Ahl, H.A.H. (2017) Botanical insecticide as simple extractives for pest control. Ujházy $\mathrm{K}$, editor. Cogent Biology, 3(1): 
1404274.

https://doi.org/10.1080/23312025.2017.1404274

[34] Zaynab, M., Sharif, Y., Abbas, S., Afzal, M.Z., Qasim, M., Khalofah, A., Ansari, M.J., Khan, K.A., Tao, L., Li, S.F. (2021). Saponin toxicity as key player in plant defense against pathogens. Toxicon, 193: 21-27. https://doi.org/10.1016/j.toxicon.2021.01.009

[35] Roopashree, K.M., Naik, D. (2019). Saponins: properties, applications and as insecticides: A review. Trends in Biosciences, 8(1): 1-14.

[36] Hussain, M., Qasim, M., Bamisile, B.S., Wang, L. (2017). Role of saponins in plant defense against the diamondback moth, Plutella xylostella (L.). Biology. https://doi.org/10.20944/preprints201706.0035.v1

[37] Qasim, M., Islam, W., Ashraf, H.J., Ali, I., Wang, L. (2020). Saponins in Insect Pest Control. In: Mérillon, J.M., and Ramawat, K.G., editors. Co-Evolution of Secondary Metabolites, Springer International Publishing, Cham., 897-924. https://doi.org/10.1007/978-3-319-96397-6_39
[38] Xiao, L., Ding, J., Zhang, J., Huang, W., Siemann, E. (2020). Chemical responses of an invasive plant to herbivory and abiotic environments reveal a novel invasion mechanism. Science of The Total Environment, 741: 140452. https://doi.org/10.1016/j.scitotenv.2020.140452

[39] Rharrabe, K., Bakrim, A., Ghailani, N., Sayah, F. (2007). Bioinsecticidal effect of harmaline on Plodia interpunctella development (Lepidoptera: Pyralidae). Pesticide Biochemistry and Physiology, 89(2): 137-45. https://doi.org/10.1016/j.pestbp.2007.05.002

[40] Barbehenn, R.V., Peter Constabel, C. (2011). Tannins in plant-herbivore interactions. Phytochemistry, 72(13): 1551-65. https://doi.org/10.1016/j.phytochem.2011.01.040

[41] Boeckler, G.A., Gershenzon, J., Unsicker, S.B. (2011). Phenolic glycosides of the Salicaceae and their role as anti-herbivore defenses. Phytochemistry, 72(13): 1497509. https://doi.org/10.1016/j.phytochem.2011.01.038 